PREPARED FOR THE U.S. DEPARTMENT OF ENERGY, UNDER CONTRACT DE-AC02-76CH03073

PPPL-3564

PPPL-3564

UC-70

Profile Modifications Resulting From Early High-Harmonic Fast Wave Heating in NSTX

J.E. Menard, B.P. LeBlanc, J.R. Wilson, S.A. Sabbagh, D. Stutman, and D.W. Swain

May 2001

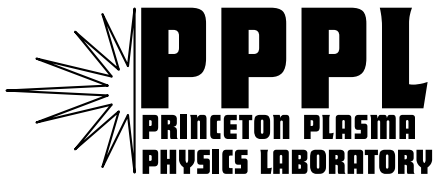

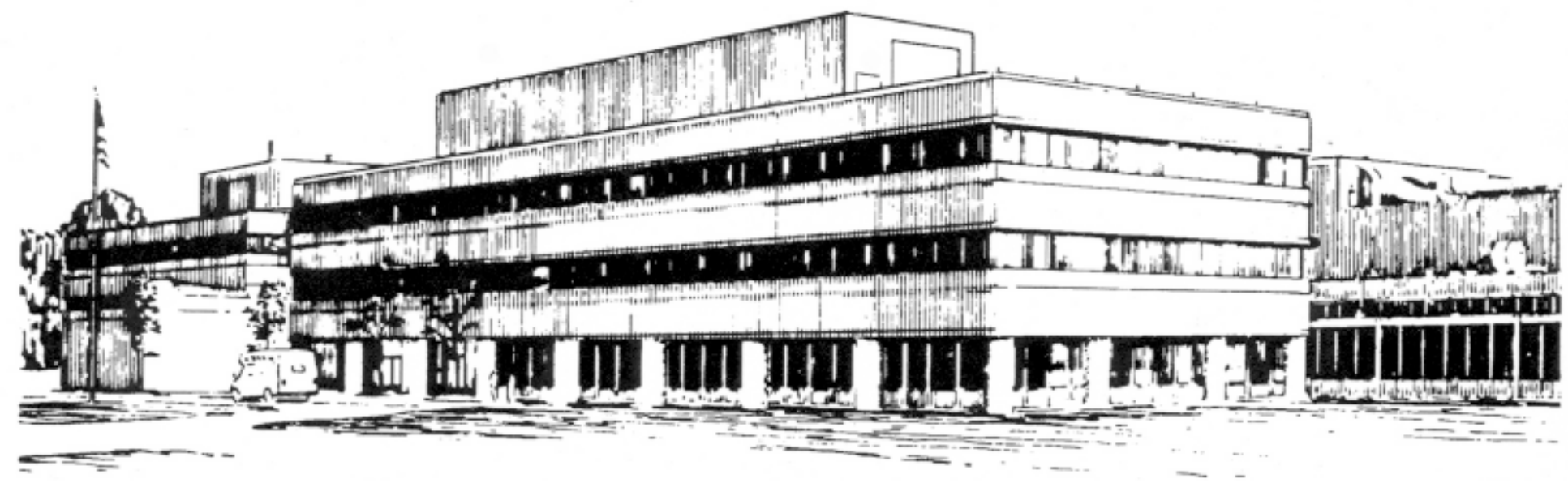

PRINCETON PLASMA PHYSICS LABORATORY PRINCETON UNIVERSITY, PRINCETON, NEW JERSEY 


\section{PPPL Reports Disclaimer}

This report was prepared as an account of work sponsored by an agency of the United States Government. Neither the United States Government nor any agency thereof, nor any of their employees, makes any warranty, express or implied, or assumes any legal liability or responsibility for the accuracy, completeness, or usefulness of any information, apparatus, product, or process disclosed, or represents that its use would not infringe privately owned rights. Reference herein to any specific commercial product, process, or service by trade name, trademark, manufacturer, or otherwise, does not necessarily constitute or imply its endorsement, recommendation, or favoring by the United States Government or any agency thereof. The views and opinions of authors expressed herein do not necessarily state or reflect those of the United States Government or any agency thereof.

\section{Availability}

This report is posted on the U.S. Department of Energy's Princeton Plasma Physics Laboratory Publications and Reports web site in Calendar Year 2001. The home page for PPPL Reports and Publications is: http://www.pppl.gov/pub_report/

DOE and DOE Contractors can obtain copies of this report from:

U.S. Department of Energy

Office of Scientific and Technical Information

DOE Technical Information Services (DTIS)

P.O. Box 62

Oak Ridge, TN 37831

Telephone: (865) 576-8401

Fax: (865) 576-5728

Email: reports@adonis.osti.gov

This report is available to the general public from:

National Technical Information Service

U.S. Department of Commerce

5285 Port Royal Road

Springfield, VA 22161

Telephone: 1-800-553-6847 or

(703) 605-6000

Fax: (703) 321-8547

Internet: http://www.ntis.gov/ordering.htm 


\title{
Profile Modifications Resulting From Early High-Harmonic Fast Wave Heating in NSTX $^{1}$
}

\author{
J. E. Menard ${ }^{a}$, B. P. LeBlanc ${ }^{a}$, J. R. Wilson ${ }^{a}$, \\ S. A. Sabbagh ${ }^{b}$, D. Stutman ${ }^{c}$, D. W. Swain ${ }^{d}$ \\ ${ }^{a}$ Princeton Plasma Physics Laboratory, Princeton, NJ 08543, USA \\ ${ }^{b}$ Columbia University, New York, NY 10027, USA \\ ${ }^{c}$ Johns Hopkins University, Baltimore, MD 21218, USA \\ ${ }^{d}$ Oak Ridge National Laboratory, Oak Ridge, TN 37831, USA
}

\begin{abstract}
Experiments have been performed in the National Spherical Torus Experiment (NSTX) to inject high harmonic fast wave (HHFW) power early during the plasma current ramp-up in an attempt to reduce the current penetration rate to raise the central safety factor during the flat-top phase of the discharge. To date, up to 2MW of HHFW power has been coupled to deuterium plasmas as early as $\mathrm{t}=50 \mathrm{~ms}$ using the slowest inter-strap phasing of $\mathrm{k}_{\|} \approx 14 \mathrm{~m}^{-1}\left(\mathrm{n}_{\phi}=24\right)$. Antenna-plasma gap scans have been performed and find that for small gaps $(5-8 \mathrm{~cm})$, electron heating is observed with relatively small density rises and modest reductions in current penetration rate. For somewhat larger gaps $(10-12 \mathrm{~cm})$, weak electron heating is observed but with a spontaneous density rise at the plasma edge similar to that observed in NSTX H-modes. In the larger gap configuration, EFIT re-constructions (without MSE) find that resistive flux consumption is reduced as much as $30 \%$, the internal inductance is maintained below 0.6 at $1 \mathrm{MA}$ into the flat-top, $q(0)$ is increased significantly, and the MHD stability character of the discharges is strongly modified.
\end{abstract}

\section{INTRODUCTION}

High-harmonic fast waves (HHFW) have been proposed as a means of efficiently heating electrons in high $\beta$ plasmas [1] and have already been used to heat Spherical Torus (ST) plasmas [2] at the multi-megawatt level in the National Spherical Torus Experiment (NSTX) [3] at PPPL, USA. At present, however, NSTX relies on ohmic current drive to reach the 1MA plasma current level required for good neutral beam absorption and confinement. In addition, many NSTX high- $\beta$ discharges have performance limited by the onset of MHD activity associated with $q(0)$ dropping below 1. Application of HHFW during the $I_{P}$ ramp-up has been attempted in an effort to raise $\mathrm{q}(0)$ and reduce $\mathrm{OH}$ flux consumption by lowering the central resistivity. Profile measurements and analysis for these experiments are presented below.

1) Work supported by the U.S. Dept. of Energy under Contract No. DE--AC02--760--CH0--3073.

(C) 2001 American Institute of Physics 


\section{EXPERIMENTAL RESULTS}

Application of early HHFW power in NSTX required growing the plasma quickly to nearly full-bore for good antenna-plasma coupling. With this discharge programming, it was possible to couple up to $2 \mathrm{MW}$ of $\mathrm{HHFW}$ power during the $\mathrm{I}_{\mathrm{P}}$ ramp-up as early as $\mathrm{t}=50 \mathrm{~ms}$. Figure 1 shows the electron temperature, density, and pressure profiles at $\mathrm{t}=97 \mathrm{~ms}$ for two inboard-limited deuterium discharges with an antenna-plasma gap of $6 \mathrm{~cm}$. The dashed lines represent ohmic reference profiles (104286), while the solid lines correspond to the HHFW heated discharge (104277). As seen in the figure, $2 \mathrm{MW}$
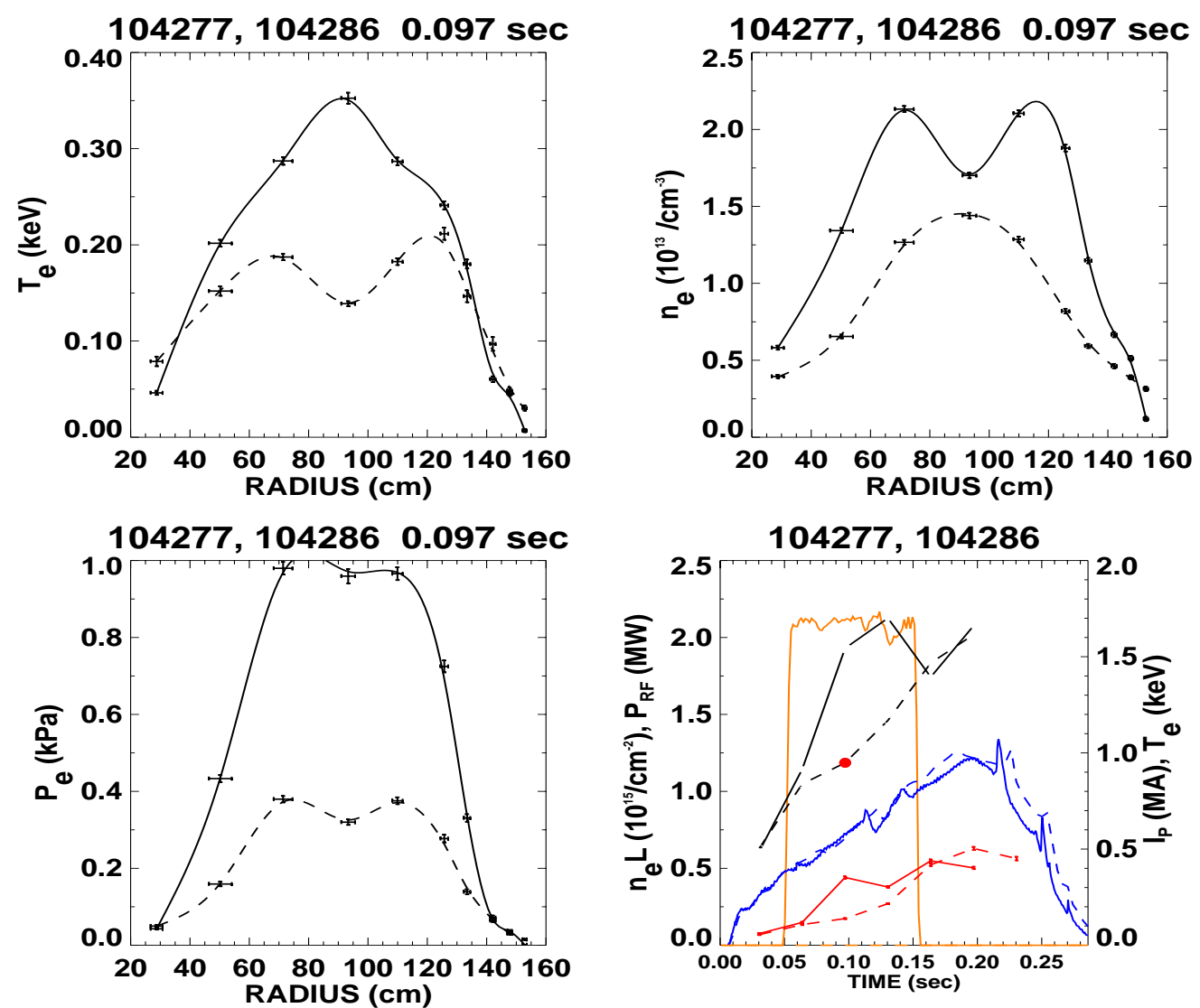

FIGURE 1. Thomson scattering profiles for ohmic (dashed) and $6 \mathrm{~cm}$ gap HHFW plasma (solid).

of HHFW power (lower right) is able to double the central electron temperature (upper left) of a $200 \mathrm{eV}$ ohmic target plasma. The figure also shows that the electron density (upper right) is doubled in the region between the axis and the core and results in a factor of 2.5 increase in the electron pressure (lower left). Achieving 1MA flat-top ohmic discharges is often difficult in NSTX at 0.3T, and an MHD "event" at 120ms interrupts the current ramp-up of both the ohmic and HHFW heated discharges (lower right). By $\mathrm{t}=130 \mathrm{~ms}$, the central Te of the HHFW heated discharge is similar to that of the ohmic reference, and the central electron pressure is $70 \%$ higher. Figure 2 shows the electron temperature, density, and pressure profiles at $\mathrm{t}=97 \mathrm{~ms}$ for the same ohmic 
reference discharge shown above, while the solid lines correspond to a HHFW heated discharge (104284) with an antenna-plasma gap of $12 \mathrm{~cm}$. As seen in the figure, for
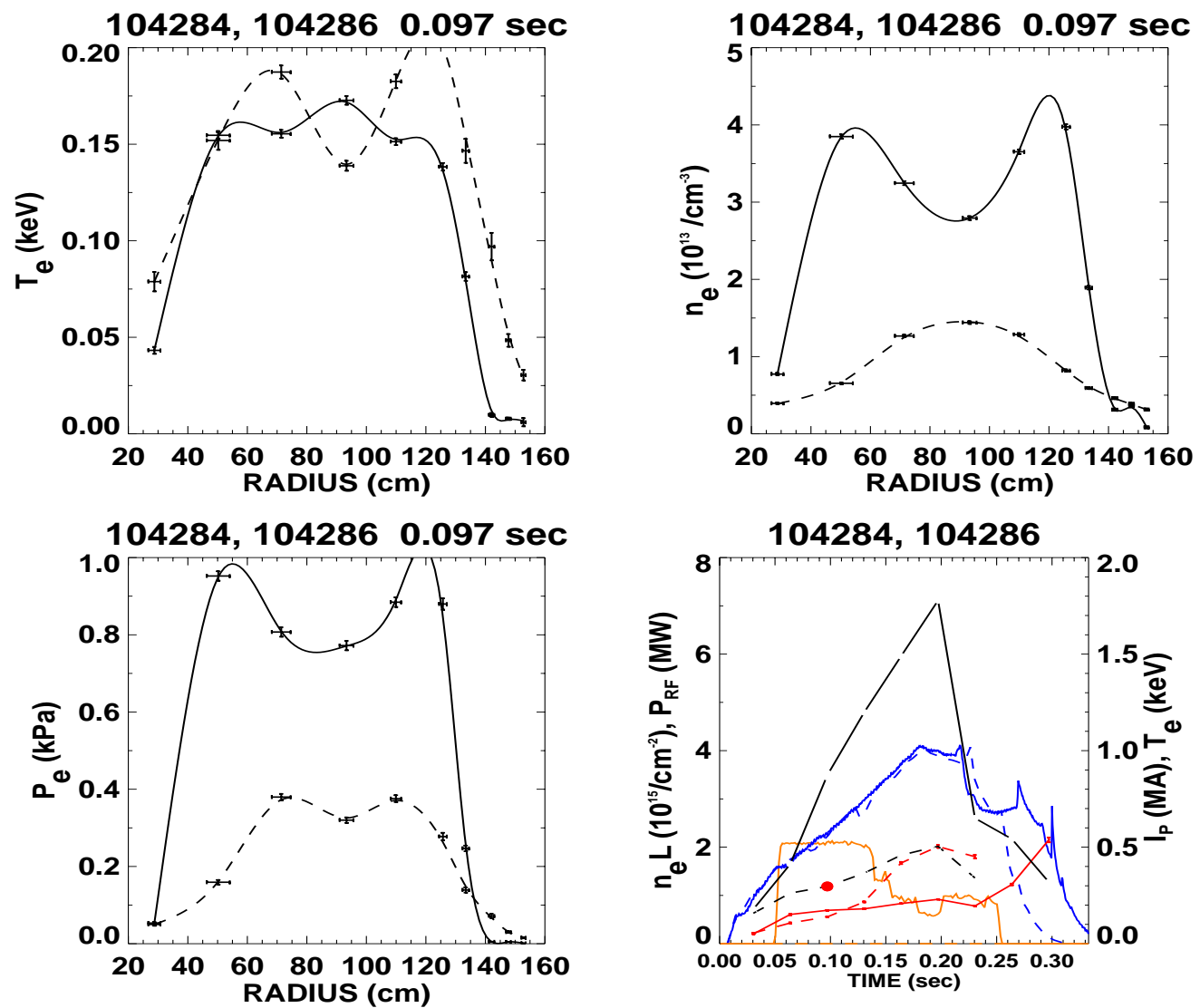

FIGURE 2. Thomson scattering profiles for ohmic (dashed) and 12cm gap HHFW plasmas (solid).

the larger antenna-plasma gap of $12 \mathrm{~cm}, 2 \mathrm{MW}$ of $\mathrm{HHFW}$ power raises the central Te only slightly, but the electron density is increased (on average) by more than a factor of 4 . The electron pressure is increased by a factor of 2 in the core, a factor of 5 near the edge, and has a hollow profile. Impurity transport modeling coupled with soft $\mathrm{X}$-ray data [4] suggests that the rapid density rise may be caused by an edge particle transport barrier similar to H-modes observed on NSTX, although the role of HHFW as a particle and ionization source cannot be ruled out. Importantly, the MHD event typical of the ohmic and $6 \mathrm{~cm}$ gap HHFW ramp-up plasmas is routinely suppressed in the $12 \mathrm{~cm}$ gap HHFW discharges. One possible explanation of this effect is suppression of locked tearing modes with high density operation. Another possibility is that high edge density modifies the edge plasma resistivity profile and thus changes the current profile evolution.

Whatever the cause, this mode of operation has allowed access to 1MA flat-top discharges with significant broadening of the equilibrium current profile as reconstructed by EFIT [5,6] (without MSE). The OH coil current swing required to reach 1MA was reduced by as much at $25 \%$ for the $12 \mathrm{~cm}$ gap discharges, and a similar fractional 
decrease in resistive flux consumption was measured by EFIT. Figure 3 shows the time evolution of the reconstructed internal inductance and $\mathrm{q}(0)$ for the $6 \mathrm{~cm}$ (dashed) and $12 \mathrm{~cm}$ (solid) gap HHFW discharges discussed above. As seen in the figure, EFIT shows
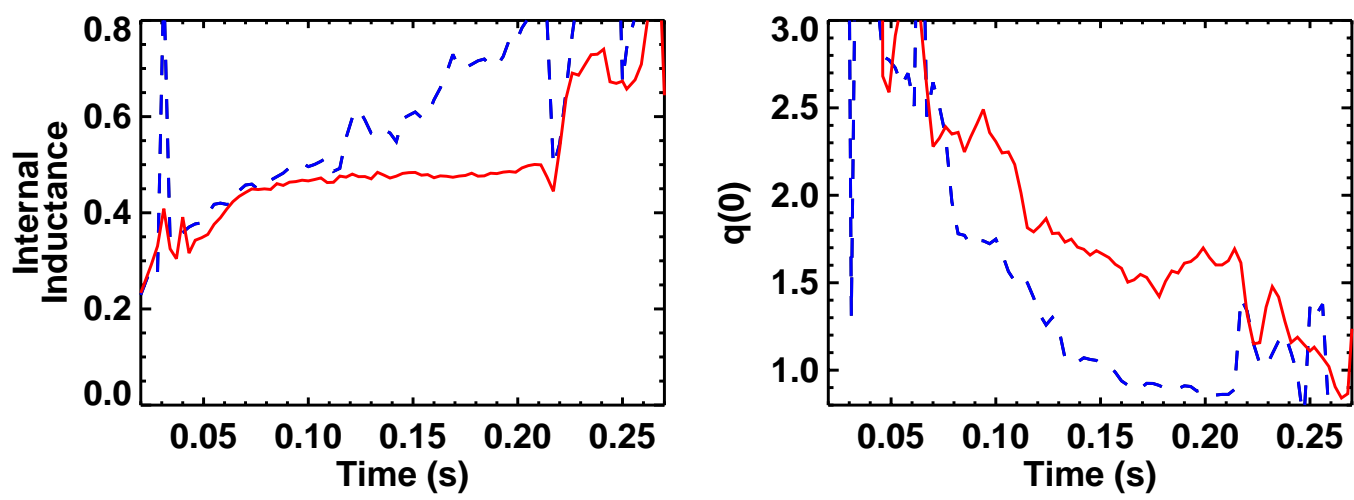

FIGURE 3. li and $\mathrm{q}(0)$ evolution for $6 \mathrm{~cm}$ (dashed) and $12 \mathrm{~cm}$ gap (solid) HHFW plasmas.

a significant increase in $\mathrm{q}(0)$ for the $12 \mathrm{~cm}$ gap case until the "reconnection-event" at $\mathrm{t}=220 \mathrm{~ms}$ disrupts the $\mathrm{I}_{\mathrm{P}}$ flat-top. In both shots, the toroidal Mirnov array and ultra-soft $\mathrm{X}$-ray data observe what is most likely a $\mathrm{m}=2 / 1$ island near $\mathrm{r} / \mathrm{a}=0.7-0.8$ just prior to reconnection. Thus, if the $12 \mathrm{~cm}$ gap discharges truly do have a broader current profile, the event which terminates the $I_{P}$ flat-top phase must be relatively insensitive to the current profile shape.

\section{CONCLUSIONS}

Experiments attempting to heat during the $\mathrm{I}_{\mathrm{P}}$ ramp-up phase using $\mathrm{HHFW}$ have been carried out in NSTX in deuterium plasmas. Discharges with an antenna-plasma gap of $6 \mathrm{~cm}$ display early central heating by HHFW, but the heating appears to be interrupted by MHD during the $I_{P}$ ramp-up. Discharges with a larger gap of $12 \mathrm{~cm}$ show much weaker central heating, achieve very high densities, very broad pressure profiles, and appear to suppress ramp-up MHD activity. For these discharges, the poloidal flux consumption is significantly reduced and the current profile as reconstructed by EFIT is broadened. This new equilibrium regime has already been used as an NBI target on NSTX, and future work will attempt to eliminate MHD activity during the early $\mathrm{I}_{\mathrm{P}}$ flat-top phase in an effort to further extend the pulse-length.

\section{REFERENCES}

1. M. Ono, Phys. Plasmas 2, 4075 (1995).

2. B. P. LeBlanc et al., this conference.

3. M. Ono et al., Nucl. Fus. 40, 557 (2000).

4. D. Stutman et al., Rev. Sci. Instrum. 70, 572 (1999).

5. L. L. Lao et al., Nucl. Fus. 25, 1611 (1985).

6. S. A. Sabbagh et al., Nucl. Fus. (2001), accepted for publication. 


\section{External Distribution}

Plasma Research Laboratory, Australian National University, Australia

Professor I.R. J ones, Flinders University, Australia

Professor J oão Canalle, Instituto de Fisica DEQ/IF - UERJ , Brazil

Mr. Gerson O. Ludwig, Instituto Nacional de Pesquisas, Brazil

Dr. P.H. Sakanaka, Instituto Fisica, Brazil

The Librarian, Culham Laboratory, England

Library, R61, Rutherford Appleton Laboratory, England

Mrs. S.A. Hutchinson, JET Library, England

Professor M.N. Bussac, Ecole Polytechnique, France

Librarian, Max-Planck-Institut für Plasmaphysik, Germany

J olan Moldvai, Reports Library, MTA KFKI-ATKI, Hungary

Dr. P. Kaw, Institute for Plasma Research, India

Ms. P.J . Pathak, Librarian, Insitute for Plasma Research, India

Ms. Clelia De Palo, Associazione EURATOM-ENEA, I taly

Dr. G. Grosso, Instituto di Fisica del Plasma, Italy

Librarian, Naka Fusion Research Establishment, J AERI, J apan

Library, Plasma Physics Laboratory, Kyoto University, J apan

Research Information Center, National Institute for Fusion Science, J apan

Dr. O. Mitarai, Kyushu Tokai University, J apan

Library, Academia Sinica, Institute of Plasma Physics, People's Republic of China

Shih-Tung Tsai, Institute of Physics, Chinese Academy of Sciences, People's Republic of China

Dr. S. Mirnov, TRINITI, Troitsk, Russian Federation, Russia

Dr. V.S. Strelkov, Kurchatov Institute, Russian Federation, Russia

Professor Peter Lukac, Katedra Fyziky Plazmy MFF UK, Mlynska dolina F-2, Komenskeho Univerzita, SK-842 15 Bratislava, Slovakia

Dr. G.S. Lee, Korea Basic Science Institute, South Korea

Mr. Dennis Bruggink, Fusion Library, University of Wisconsin, USA

Institute for Plasma Research, University of Maryland, USA

Librarian, Fusion Energy Division, Oak Ridge National Laboratory, USA

Librarian, Institute of Fusion Studies, University of Texas, USA

Librarian, Magnetic Fusion Program, Lawrence Livermore National Laboratory, USA

Library, General Atomics, USA

Plasma Physics Group, Fusion Energy Research Program, University of California at San Diego, USA

Plasma Physics Library, Columbia University, USA

Alkesh Punjabi, Center for Fusion Research and Training, Hampton University, USA

Dr. W.M. Stacey, Fusion Research Center, Georgia Institute of Technology, USA

Dr. J ohn Willis, U.S. Department of Energy, Office of Fusion Energy Sciences, USA

Mr. Paul H. Wright, Indianapolis, Indiana, USA 
The Princeton Plasma Physics Laboratory is operated by Princeton University under contract with the U.S. Department of Energy.

\author{
Information Services \\ Princeton Plasma Physics Laboratory \\ P.O. Box 451 \\ Princeton, NJ 08543
}

Phone: 609-243-2750

Fax: 609-243-2751

e-mail: pppl_info@pppl.gov

Internet Address: http://www.pppl.gov 